\title{
Visualization Resources: To Better Utilize Lab-Time and to Enhance Teaching Introductory Chemistry Laboratory
}

\author{
Tawfik A. SALEH \\ King Fahd University of Petroleum \& Minerals \\ Kingdom of Saudi Arabia \\ e-mail: abo_norl@hotmail.com
}

(Received: September 22, 2008; Accepted for publication: April 23, 2009; Advance publication: June 2, 2009)

This study investigates the importance of visualization resources to help students for mental preparation and laboratory-time utilization. The results of experimental and control groups showed that students' understanding of the concepts and experimental procedures improves after reviewing the visualization resources $(\mathrm{t}=8.52$ for quizzes and 4.31 for reports, $\mathrm{p}<0.001$, effect size $=1.2)$. The results of the study suggested that the resources could serve as a mental preparation tool.

Keywords: Visualization resources, Utilize lab-time, Enhance teaching, First-year undergraduate, General chemical education

\section{Introduction}

For science and non-science majors, a general chemistry practical course for undergraduate teaching is an essential element for learning and building up the knowledge. One of the most important keys in laboratory teaching is to prepare students' minds for learning new concepts as well as new skills. Teaching chemistry laboratory demands more work from students before the laboratory performance in order to develop a prepared mind but without cognitive overload [1]. Over the years, students have been mentally prepared by the traditional short lectures presented at the start of the laboratory period, demonstrations, reading assignments, graded quizzes, and other pre laboratory assignments. It was shown that the learners' acquisition of technical skills depends on the mental view of the skills to be learned [2]. Pickering described pre-lab quizzes or pre-lab talks to prepare students for laboratory work as the classical way [3]. Palma showed that videotapes shorten in-lab instruction [4]. The use of computerassisted learning has been reported in the determination of the percent oxygen in a sample of potassium chlorate [5] and in four organic chemistry experiments [6].

The display of information or procedure of doing experiments can be done before lab-time using videos, photographs and figures as visualization resources. The main objectives of this display are to provide the students a visual means of processing the information and to show them the procedure of experiment. The students have to watch the resources before they attend the laboratory.

In this study the pre-laboratory use of videos, photographs and figures is researched. This study investigates whether these materials can help better utilizing lab-time and can be an effective way of mental preparation for learning new concepts and skills.

\section{Methodology}

\subsection{Laboratory Description}

The general chemistry course consists of two parts; class and laboratory. In the laboratory students perform experiments during the whole semester; four hours a week. There are many sections since most freshmen students have to take this course. During this study, some sections had been assigned to use visualization resources before doing the experiment (those are named experimental groups in this study). The students of the other sections were not able to use them (those are named control groups in this study).

\subsection{Procedure of Using Resources}

The procedure of using the visualization resources was given and explained to the students of the experimental 
group only. Visualization resources, such as videos, photographs, figures and some brief instructions of each experiment, were available to students of the experimental group. Students were asked to review the material before coming to the lab to perform the experiment. The resources which were available to the students of experimental groups contain videos to show how to perform the experiments. Also, it contains photographs and figures to show how to use the equipments and glassware. Safety videos were also available to help students understand the laboratory rules and precautions.

\subsection{Data Collection}

Time during which students of both groups performed the experiments was counted. All students of both groups were informed of a quiz related to the experiment. In both experimental and control groups, students had to turn in individual report sheets. In addition, questionnaires were distributed to students of the experimental group. EXCEL and MINITAB software were used for statistical analyses.

\subsection{Evaluation}

The evaluation of this study consisted of two parts: the statistical analysis comparison of the lab-time and report sheets between the experimental and control groups. The other part is the students' attitudes.

\section{Results and Discussion}

\subsection{Analysis of Lab-Time}

The time, during which each experiment was performed, had been counted for both groups. Then, the average was taken for each group per experiment. This was done without pushing students or even telling them that time is counted. Also, both groups did the same procedures, calculations and each student turned in an individual report sheet for each experiment. Figure 1 shows that experimental groups took significantly less time to perform the experiments because they had better mental preparation via visualization resources comparing with control groups which did not use them. Better mental preparation shortens the time for lab instruction that is given at the beginning of each lab and shortens the time needed to perform the experiment. Experience indicates there were fewer questions regarding techniques from students of experimental groups comparing with those of control groups. This interpretation should be linked with statistical analysis of the report sheets and quizzes in the following section which can clarify that experimental groups gain better understanding.

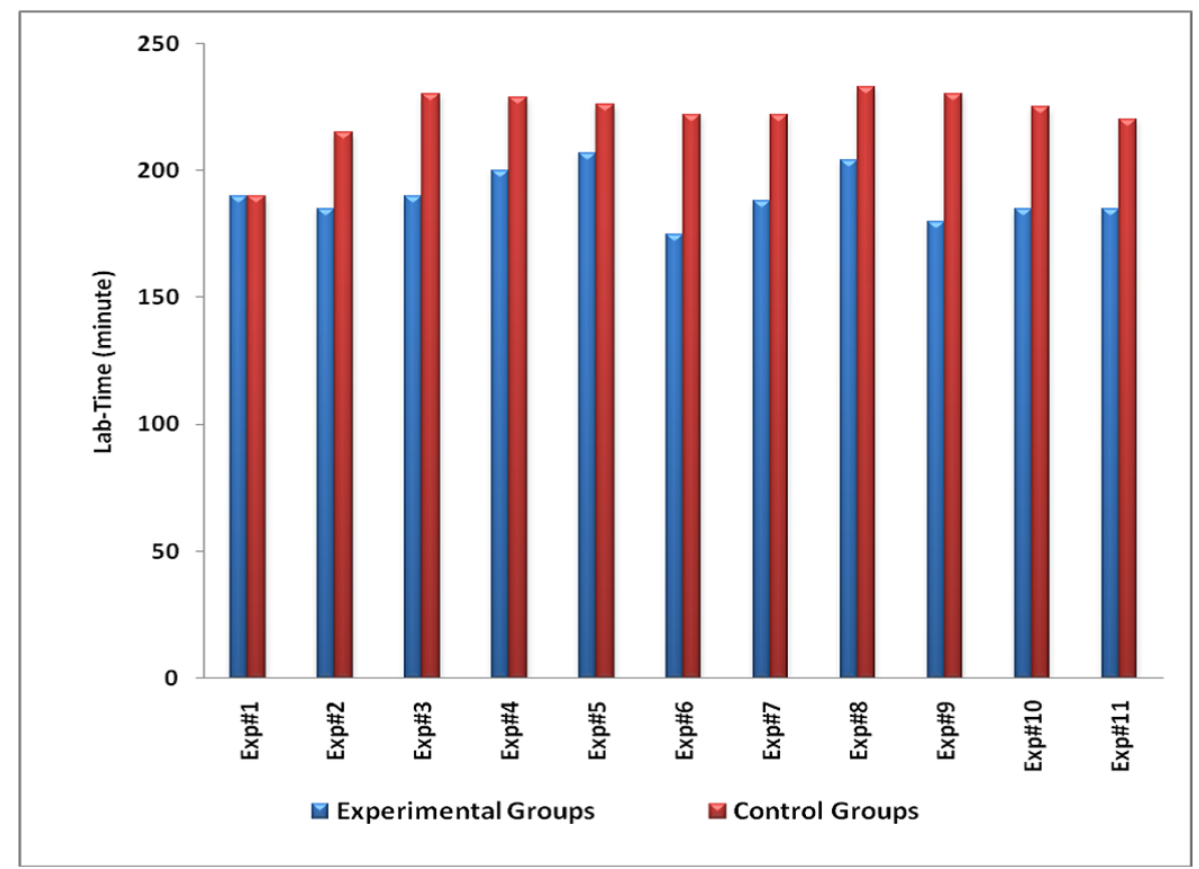

Figure 1. Average of the Lab-Times during which Students Performed the Experiments 


\subsection{Analysis of Report Sheets}

The statistical analysis of the report sheets is of great value by which one can compare the experimental group with the control group. The data that was collected from the report sheets includes skills of performance, observation, recording the measurements with the correct units, and calculations to reach the objectives of each experiment. This includes, for example, the students' ability to select the correct graduated cylinders to measure specific amounts of volumes and to read and record the value to correct significant figures. This is one simple example to clarify what kind of data was collected from the report sheets although each experiment's report has different valuable data which could be used to compare the experimental groups with control groups. As shown in Figure 2, students of experimental groups got higher per- centages in almost all the experiments. Quizzes, also, contained conceptual questions that could indicate which group had deeper mental preparation.

Cumulative statistical analysis of the report sheets' averages shows that; t-test is higher than the critical value. P-value is less than 0.05 . In addition, the effect size was also calculated. It indicates that using visualization resources can significantly enhance the efficiency and students' understanding. An effect size of 1.2 (Table 1), means that the median students' performance is significantly improved from the $50^{\text {th }}$ percentile in the control group, to approximately more than $80^{\text {th }}$ percentile in the experimental group. One indication of the higher means and lower standard deviation for the experimental groups comparing with those of the control groups is that the visualization resources provide a valuable way to understand the concepts.

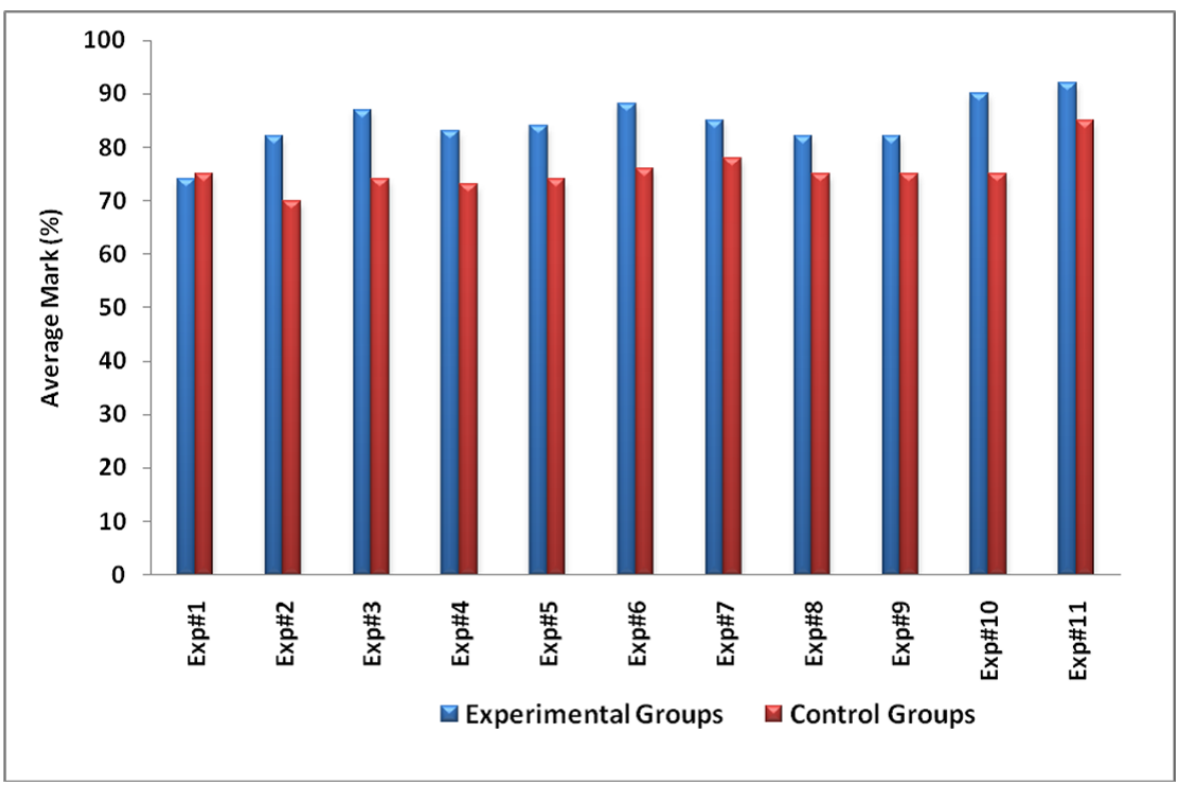

Figure 2. Average Marks of the Report Sheets

Table 1. Statistical Analysis for Comparison

\begin{tabular}{|c|c|c|c|c|c|c|c|}
\hline & \multicolumn{2}{|c|}{ Experimental Group } & \multicolumn{2}{|c|}{ Control Group } & \multicolumn{3}{|c|}{ Statistical Values } \\
\hline & Mean & S.D. & $\overline{\text { Mean }}$ & S.D. & $\begin{array}{l}t \text {-test } \\
\text { (critical value } \\
\text { at } \mathrm{P}=0.05)\end{array}$ & $p$-value & ct size* \\
\hline Written Quizzes & 81.3 & 5.9 & 51.8 & 10.7 & $8.52(2.22)$ & $6.8^{-6}$ & 1.1 \\
\hline Experiments Reports & 84.2 & 5.7 & 75.6 & 7.4 & $4.31(2.22)$ & $8.0^{-4}$ & 1.2 \\
\hline
\end{tabular}

* S.D. :Standard Deviation

* Calculated According to the following equation [7]

Effect Size $=\frac{\text { Mean }_{\text {treatmentgroup }}-\text { Mean }_{\text {contrlgroup }}}{\text { StandardDeviation }_{\text {controlgroup }}}$ 
Table 2. Students' Responses to How Visualization Resources Help

\begin{tabular}{clcc}
\hline & \multicolumn{1}{c}{ I believe that visualization resources helped me in: } & Agree \% & Disagree \% \\
\hline 1. & mental preparation for the experiments & 85 & 15 \\
2. & understanding the experiments' concepts & 79 & 21 \\
3. & understanding the procedures of performing the experiment & 73 & 27 \\
4. & understanding how to use some chemical equipments, glassware & 76 & 24 \\
5. & visual understanding of the safety rules & 85 & 15 \\
6. & following the recommended precautions & 79 & 21 \\
7. & improving my performance, skills and abilities & 82 & 18 \\
8. & increasing my independence and motivation & 67 & 33 \\
9. & increasing the efficiency and effectiveness of discussion & 85 & 15 \\
10. & giving chance to review the material at any place and time appropriate to me & 100 & 0 \\
\hline
\end{tabular}

\subsection{Questionnaire}

At the end of the course, the students of the experimental groups fill out a course evaluation survey that measures the students' attitudes to different aspects of how the resources were helpful. The terms' meanings in the survey were explained to the students.

Table 2 shows the percentages of the students' responses to the questionnaire. Their responses to mental preparation show that $85 \%$ agreed that the resources were helpful. Also, the majority agreed that they helped them in understanding the concepts and procedures. In addition, $82 \%$ agreed about the improvement of the performance.

\section{Conclusion}

The data from this study support the conclusion that the visualization resources help and motivate students develop mental preparation. Statistical analysis shows that they are significantly important to maximize the utilization of the lab-time and in the same way to improve the practical skills. They represent an additional teaching and learning tool which supplements the teachers' explanations and students' literacy.

\section{Future Work}

The future work will be to gather more direct evidence of the mental images students develop as a result of the use of the visualization resources.
The author would like to thank the chemistry lab instructors who assisted in this study and grateful to the reviewers for their helpful comments and guidance. Any opinions or suggestions can kindly be sent to the author via email and would be highly appreciated.

\section{References}

[1] Gagne, R. M., The Conditions of Learning, Holt, Rinehart and Winston, New York (1970).

[2] Jonstone, A. H., Letton, K. M., Practical Measures for Practical Work, Educ. Chem., 29, 81-83 (1991).

[3] Pickering, M., What goes on in students' heads in lab?, J. Chem. Educ., 64, 521-523 (1987).

[4] Palma, R. J., A technique-oriented freshman laboratory program, J. Chem. Educ., 52, 116-117 (1975).

[5] Moore, C., Smith, S., Avner, R. A., Facilitation of laboratory performance through CAI, J. Chem. Educ., 57, 196-198 (1986).

[6] Wiegers, K. E., Smith, S. G., The use of computerbased chemistry lessons in the organic laboratory course, J. Chem. Educ., 57, 454-456 (1980).

[7] Cohen, J., Statistical power analysis for the behavioral sciences., 2nd ed., Lawrence Earlbaum Associates, Hillsdale, NJ (1988). 